Check for updates

Cite this: RSC Adv., 2018, 8, 33383

Received 11th May 2018

Accepted 27th August 2018

DOI: $10.1039 / \mathrm{c} 8 \mathrm{ra04015j}$

rsc.li/rsc-advances

\section{Cadmium tolerance and accumulation characteristics of wetland emergent plants under hydroponic conditions $\uparrow$}

\author{
Yangyang Wang, ${ }^{\text {ab }}$ Ningqing Lv, ${ }^{\mathrm{b}}$ Xuhui Mao, (D) ${ }^{\mathrm{c}}$ Zheng Yan, ${ }^{\mathrm{d}}$ Jinsheng Wang, ${ }^{\mathrm{e}}$ \\ Wenbing Tan, ${ }^{\mathrm{b}}$ Xiang Li, ${ }^{\mathrm{b}}$ Hui Liu, ${ }^{\mathrm{b}}$ Lei Wang (D) ${ }^{\star b}$ and Beidou $\mathrm{Xi}^{* \mathrm{~b}}$
}

For the purpose of screening a potential $\mathrm{Cd}$-hyperaccumulator for $\mathrm{Cd}$-contaminated soil in paddy fields, four kinds of wetland emergent plants (Iris sibirica L., Acorus calamus L., Typha orientalis Presl and Cyperus alternifolius L.) were investigated for their cadmium tolerance and accumulation characteristics under hydroponic conditions. The physiological responses of plants, $\mathrm{Cd}$ concentration in tissues, $\mathrm{Cd}$ accumulation, bioaccumulation factor (BCF) and translocation factor (TCF) were investigated to evaluate the abilities of wetland emergent plants to absorb and accumulate $\mathrm{Cd}$. In comparison with the other selected emergent plants, Iris sibirica L. has the strongest Cd-tolerance for the absence of $\mathrm{Cd}$ toxic symptoms and a $\mathrm{Cd}$ concentration as high as $127.3 \mathrm{mg} \mathrm{kg}^{-1}$ in shoots. Due to its large biomass, the $\mathrm{Cd}$ accumulation could reach up to $9.4 \mathrm{mg}$ per plant in roots and $5.7 \mathrm{mg}$ per plant in shoots, respectively. Iris sibirica L. possesses the highest TCF, and its BCF for $\mathrm{Cd}$ increased with increasing concentration of spiked $\mathrm{Cd}$ in the hydroponic solutions. The results indicate that Iris sibirica L. is a potential $\mathrm{Cd}$ hyperaccumulator that may have a strong capacity for extracting $\mathrm{Cd}$ from $\mathrm{Cd}$-contaminated paddy soils.

\section{Introduction}

Heavy metals that exceed concentrations that the natural environment can bear, can disrupt the balance of the ecosystem and pose a health risk to humans. ${ }^{1}$ Currently, in the world in general and in China specifically, determining how to control and mitigate heavy metal pollution has become an increasingly prominent issue. Once heavy metals enter into the soil environment, the self-cleaning function of the soil alone, in the short term, cannot effectively eliminate their impact on the ecological environment. Cadmium (Cd) is one of the most hazardous and ubiquitous contaminants in soil and water generated from various sources including industrial and municipal wastes, combustion of fossil fuels and use of agro-chemicals. ${ }^{2,3} \mathrm{Cd}$, with strong mobility, can easily enter the surrounding environment ${ }^{4,5}$ and accumulate in plants and animals, and ultimately be

${ }^{a}$ Key Laboratory of Clean Energy of Liaoning, College of Energy and Environment, Shenyang Aerospace University, Shenyang 110136, P. R. China

${ }^{b}$ State Key Laboratory of Environmental Criteria and Risk Assessment, Chinese Research Academy of Environmental Sciences, Beijing 100012, P. R. China. E-mail: wanglei01@craes.org.cn; xibeidou@yeah.net

${ }^{c}$ School of Resources and Environmental Science, Wuhan University, Hubei, Wuhan 430070, P. R. China

${ }^{d}$ Chinese Society for Environmental Sciences, Beijing 100012, P. R. China

'Shenzhen Long Cheng High-tech Environmental Protection Co., Ltd., Shenzhen, Guangdong 518063, China

$\dagger$ Electronic supplementary information (ESI) available. See DOI: 10.1039/c8ra04015j enriched in human bodies, resulting in damage to human health. ${ }^{6,7}$ Therefore, it is important and urgent to develop costeffective methods to decontaminate Cd from soils.

Phytoremediation of soil was developed in the early 1970 s to inhibit excessive accumulation of metals in soils on the basis of the theory that use of green plants can effectively remove contaminants from soil or to lower mobility of contaminants., Because phytoremediation has the benefits of low cost, ease of operation, beneficial landscape effects, environment-friendliness and sustainability, increasing numbers of countries and enterprises are adopting this technology for soil remediation. ${ }^{10}$ The key to phytoremediation is the selection of the appropriate heavy metal hyperaccumulators. Some terrestrial plants, such as Thlaspi caerulescens, Sedum alfredii Hance, Elsholtzia splendens Nakai and Commelina communis are known as hyperaccumulators for $\mathrm{Cd}$, showing favorable hypertolerant abilities and extracting rates for the remediation of Cd-contaminated soils. ${ }^{2,11,12}$ However, the slow growth rate, relatively low biomass and regional type of plants often limited the extensive application of these terrestrial hyperaccumulators. ${ }^{13}$ Moreover, for the large numbers of Cd-contaminated paddy fields in the south of China, the documented terrestrial Cd-hyperaccumulators are not appropriate choice for in situ phytoremediation. Phytoremediation can absorb heavy metals in water for a long time and concentrate heavy metals in plants. Compared with biochar remediation and microbial remediation, phytoremediation is more economical and energy saving, with less influence factors and easier for centralized treatment. ${ }^{31,32}$ 
Previous studies also suggested that a variety of wetland emergent plants were particularly useful in removing organic and inorganic pollutants from polluted waters. ${ }^{14}$ The wetland emergent plants are known for their well-developed root systems, rapid growth rate and high biomass in a reproductive cycle, thereby have demonstrated favorable capabilities for the removal of heavy metals in wastewater and surface water. For example, Phragmites australis, Typha capensis and Spartina maritime habitated in the estuaries with elevated levels of heavy metals reportedly exhibited significantly higher concentrations of metals in their roots for four elements (Cd, $\mathrm{Cu}, \mathrm{Pb}$, and $\mathrm{Zn}){ }^{15}$ Heavy metal cadmium is concentrated by rice and harmful to human body. Cadmium is the most toxic to plants in three heavy metals such as copper, zinc and cadmium. The results of the study showed that plants have certain selective tolerance to these three heavy metals. The results of the study also showed that plant has more obvious accumulation above three heavy metals, and the accumulation contents in sequence were $\mathrm{Zn}>$ $\mathrm{Cu}>\mathrm{Cd}$. Echinochloa polystachya, as a potential hyperaccumulator in tropical areas, was found to have the capability of extracting $\mathrm{Cd}$ from the Cd-contaminated soil or wetlands. ${ }^{\mathbf{1 6}}$ Solanum nigrum L. and Rorippa globosa (Turcz.) have been recognized as Cd-hyperaccumulators because the $\mathrm{Cd}$ accumulations in Solanum nigrum L. and Rorippa globosa were 103.8$107.0 \mathrm{mg} \mathrm{kg}^{-1}$ in their stems and $124.6-150.1 \mathrm{mg} \mathrm{kg}^{-1}$ in their leaves, respectively. ${ }^{2}$ Although some wetland emergent plants have shown the capability of uptaking heavy metals, systematic studies regarding the cadmium hyperaccumulation in wetland emergent plants are very lacking.

In order to clarify the tolerance and accumulation characteristics of wetland emergent plants to toxic heavy metals, four kinds of wetland emergent plants, which are extensively used for ecological landscape improvement and constructed wetland engineering, were selected and cultivated with hydroponic solution containing $\mathrm{Cd}^{2+}$. The hydroponic culture rather than soil culture was chosen for the cultivation of plants is to avoid the interference from the soil. Cd uptake by plant and Cd adhesion in soil are closely associated with soil texture and microbial conditions, and the heterogeneity of soil often caused the difficulties in quality control of the experimental soils. In contrast, the hydroponic condition allows a precise control on the culture parameters. The objectives of this study were to evaluate the Cd-tolerance ability of the selected four wetland emergent plant species (i.e., Iris sibirica L., Cyperus alternifolius L., Typha orientalis Presl and Acorus calamus L.), and to assess their capabilities for Cd uptake. We hope that the present study not only gives an insight into the Cd-uptake behaviors of the wetland emergent plants, but also provide useful hyperaccumulators for the phytoremediation of Cd-contaminated soils in paddy fields.

\section{Materials and methods}

\subsection{Wetland emergent plants and hydroponic culture}

Iris sibirica L., Acorus calamus L., Typha orientalis Presl and Cyperus alternifolius L., four kinds of common emergent plants, were selected for this study. The plants, six months old and with visually similar biomass, were carefully transplanted from a nursery located in the Daxing district, Beijing to the green house for hydroponic culture in September 2015. The plants were washed thoroughly with running tap water to remove remaining sediment and rinsed with deionized water. ${ }^{15}$ The aforementioned wetland emergent plants were cultured in polyvinyl-chloride buckets (20.0 cm diameter, $30.0 \mathrm{~cm}$ length), and each bucket was placed with three plants and $10 \mathrm{~L}$ hydroponic solution. Plants were exposed to five different $\mathrm{Cd}$ concentrations $\left(0,5.0,10.0,15.0,25.0 \mathrm{mg} \mathrm{L}^{-1}\right)$. For each kind of plant, experiments were conducted in triplicate for every $\mathrm{Cd}$ concentration. Deionized water was added to maintain constant volume of solution every day, and the nutrient solutions were completely replaced every week. The experiment was carried out in a green house located in the Shunyi district, Beijing, lasting for 60 days before harvesting (from 1st September 2015 to 31st October 2015). The temperature range in the green house recorded for the culture period was from 18.0 to $22.0^{\circ} \mathrm{C}$, and the average photoperiod was $\sim 11 / 13 \mathrm{~h}$ (light/dark). The nutrient solution for culturing plants included $5.0 \mathrm{mmol} \mathrm{KNO}_{3}$, $5.0 \mathrm{mmol} \mathrm{Ca}\left(\mathrm{NO}_{3}\right)_{2} \cdot 4 \mathrm{H}_{2} \mathrm{O}, 1.0 \mathrm{mmol} \mathrm{KH}_{2} \mathrm{PO}_{4}, 2.0 \mathrm{mmol}$ $\mathrm{MgSO}_{4} \cdot 7 \mathrm{H}_{2} \mathrm{O}, 9.0 \mathrm{mmol} \mathrm{MnCl}_{2} \cdot 4 \mathrm{H}_{2} \mathrm{O}, 0.8 \mathrm{mmol} \mathrm{ZnSO}_{4} \cdot 7 \mathrm{H}_{2} \mathrm{O}$, $0.3 \mathrm{mmol} \mathrm{CuSO} \cdot 5 \mathrm{H}_{2} \mathrm{O}, 4.0 \mathrm{mmol} \mathrm{H}_{3} \mathrm{BO}_{3}, 0.01 \mathrm{mmol} \mathrm{H}_{2}-$ $\mathrm{MoO}_{4} \cdot \mathrm{H}_{2} \mathrm{O}$ and $0.8 \mathrm{mmol} \mathrm{Fe}_{2}\left(\mathrm{SO}_{4}\right)_{3}$ citrate as the iron source. ${ }^{17}$

\subsection{Sample collection and preparation}

Plant samples after 60 days of hydroponic culture were collected from the same cylinder, washed with deionized water and $0.01 \mathrm{M} \mathrm{HCl}$, and then dissected into roots (including rhizomes and roots sensu stricto), stems, and leaves in the laboratory. Each respective organ was oven dried at $70.0{ }^{\circ} \mathrm{C}$ for $72 \mathrm{~h}$ to remove the moisture, ground to fine powder using an analytical mill and homogenized to ensure uniform element distribution. After passing through a $160.0 \mu \mathrm{m}$ diameter sieve, the powder was weighed and ready for subsequent $\mathrm{Cd}$ analysis. ${ }^{18}$

\subsection{Analytical methods}

To determine the metal concentrations in plant, $0.2 \mathrm{~g}$ powder sample was digested in a Teflon digestion vessel. The digestion solution was composed of $7.0 \mathrm{ml} 65 \mathrm{wt} \%$ nitric acid $\left(\mathrm{HNO}_{3}\right)$ and $1.0 \mathrm{ml} 30 \mathrm{wt} \%$ hydrogen peroxide $\left(\mathrm{H}_{2} \mathrm{O}_{2}\right) .{ }^{19}$ The vessels were then capped and fitted into rotor segments and inserted into the microwave digestion system. The samples were radiated for 35 min. Upon cooling, the vessels were uncapped and solutions were transferred into $100 \mathrm{ml}$ volumetric flasks. The analysis of samples was carried out using an Inductively Coupled Plasma Mass-Spectrophotometer (ICP-MS) instrument (Agilent 7500cx). $2 \mathrm{wt} \%$ nitric acid was used as a blank.

\subsection{Bioaccumulation factor and translocation factor}

The capacities of the four plants to accumulate Cd were evaluated based on the Cd uptake per plant, the bioaccumulation factor (BCF), and the translocation factor (TCF). BCF this study is defined as the ratio of total metal concentration in shoots to that in water, which is an indicator of the ability to uptake and transport metals to the shoots; $;^{20,21}$ TCF is defined as the ratio of heavy metal concentration in the shoot to that in the root. ${ }^{22}$ 


\subsection{Statistical analysis}

All values described in this study are means of three replicates. Analysis of variance (ANOVA) was done by using a statistical software, Statistical Product and Service Solutions (SPSS) version 22.0, to determine the significant difference between the mean values. A least significant difference test (LSD test) was used for the comparison of changes at $P<0.05$. Also, hierarchical cluster analysis (HCA) was performed on Cd accumulation and TCF with the Ward's method, which uses the squared Euclidean distance as a similarity measure.

\section{Results and discussion}

\subsection{Physiological responses of wetland emergent plants}

Plants may show visible Cd toxic symptoms such as necrosis and whitish-brown chlorosis under Cd stress. ${ }^{12}$ Therefore, the appearance of plants can be used to assess the Cd-induced damage to the growth of wetland emergent plants. After 60 days of exposure, the appearances of the plants are shown in Fig. 1. Iris sibirica L. did not show symptoms such as necrosis and whitish-brown chlorosis under the stress of all Cd concentrations, which suggested that Iris sibirica L. had a strong tolerance to Cd stress. Cyperus alternifolius L. showed slight chlorosis and little necrosis until the Cd concentration was up to $15.0 \mathrm{mg} \mathrm{L}^{-1}$. Typha orientalis Presl appeared serious whitishbrown chlorosis, showing significant Cd toxicity under all the Cd treatments. Acorus calamus L. showed serious Cd toxic symptoms under all Cd treatments. As a hyperaccumulator, the requisite is that the plant has a high tolerance to heavy metal stresses, which enables them to tolerate and evolve resistance to adverse conditions that are toxic to the majority of plants. ${ }^{23}$ From the results, it can be deduced that Iris sibirica L. has a very strong tolerance to Cd contamination; such hypertolerance is a pivotal property that makes hyperaccumulation possible.

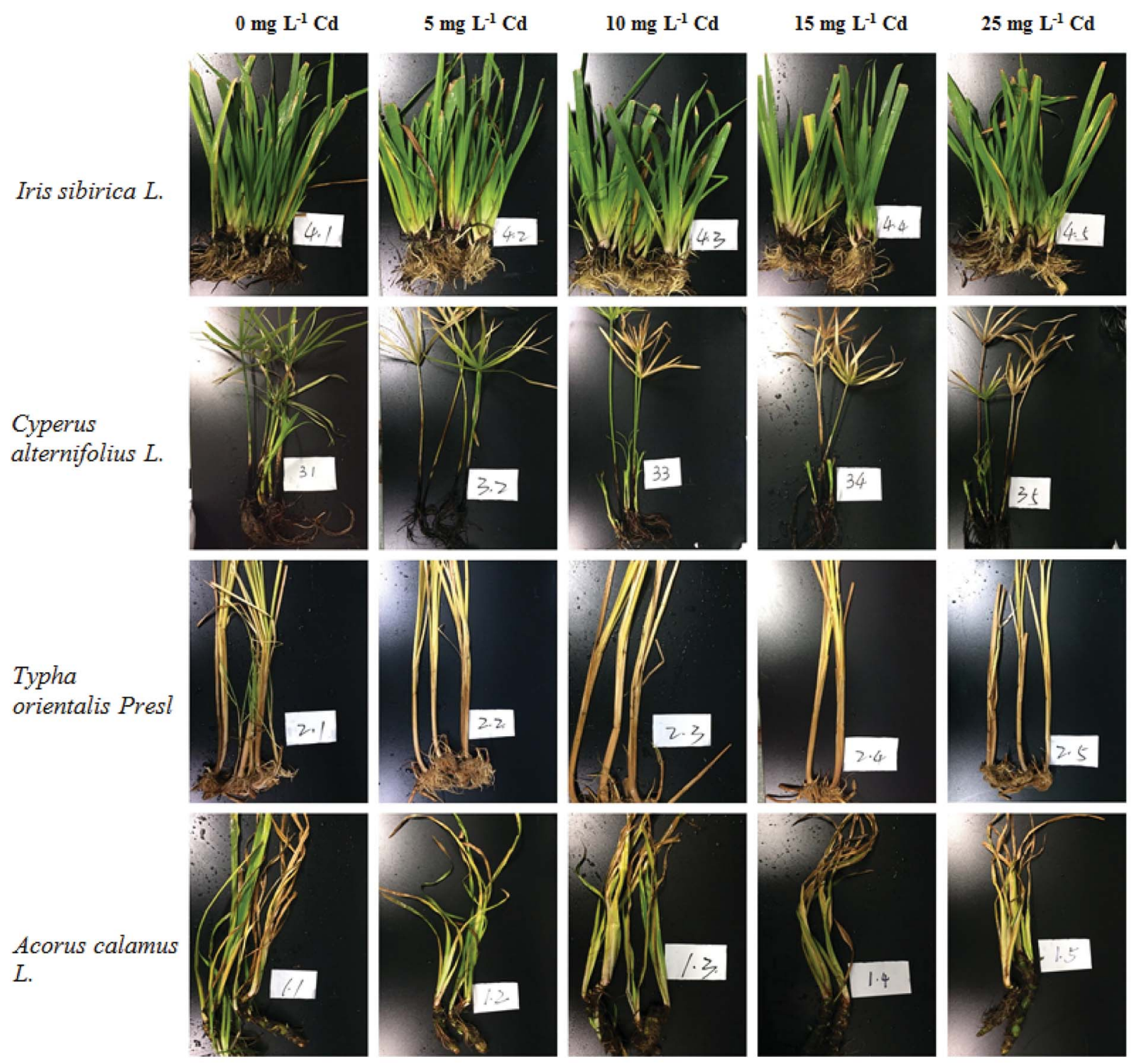

Fig. 1 Growth of wetland emergent plants under the stress of $\mathrm{Cd}$. 


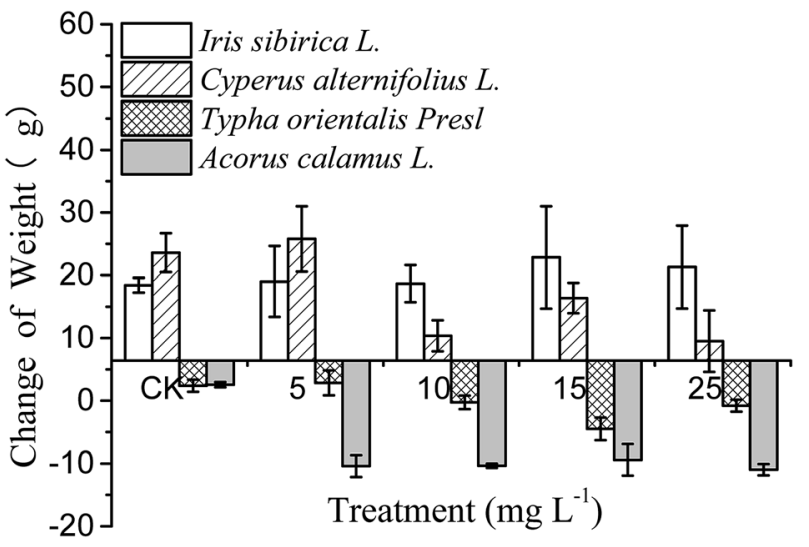

Fig. 2 Changes of total biomass under the stress of $\mathrm{Cd}$. Data are means \pm S.D. $(n=3)$.

As for the biomass changes of Iris sibirica L. (Fig. 2), the dry weight increment under $\mathrm{Cd}$ treatment was about $20.0 \mathrm{~g}$ compared with the control group. Larger biomass could lead to a growth dilution effect on heavy metals and subsequently alleviate the metal phytotoxicity, ${ }^{24}$ therefore the increased biomass in Iris sibirica L. can further mitigated the toxicity of $\mathrm{Cd}$. Meanwhile, plants with larger biomasses may provide more active absorption sites or metal binding sites. ${ }^{33}$ The biomass changes of both Cyperus alternifolius L. and Typha orientalis Presl showed same trend: they both reached the largest values at the $\mathrm{Cd}$ level of $5.0 \mathrm{mg} \mathrm{L}^{-1}$, and then decreased distinctly. This observation suggested that $\mathrm{Cd}$ concentrations higher than
$10.0 \mathrm{mg} \mathrm{L}^{-1}$ can inhibit the growth of Cyperus alternifolius $\mathrm{L}$. and Typha orientalis Presl greatly. Relative to the control one, the dry weight change of Acorus calamus $\mathrm{L}$. fell down to negative values when the $\mathrm{Cd}$ level exceeded $5.0 \mathrm{mg} \mathrm{L}^{-1}$. It suggested that the treatment of Cd could greatly depress the growth of Acorus calamus L. under Cd stress, and exerted a remarkably deleterious effect on the biomass change of Acorus calamus $\mathrm{L}$. According to the above results, the Cd-tolerance abilities of the emergent plant species tested in this study followed the order: Iris sibirica $\mathrm{L}$. > Cyperus alternifolius $\mathrm{L}$. $\gg$ Typha orientalis Presl $>$ Acorus calamus $\mathrm{L}$.

\subsection{Cd concentrations in wetland emergent plant tissues}

The amount and distribution of $\mathrm{Cd}$ accumulated in the emergent plants under various $\mathrm{Cd}$ treatments are depicted in Table S1, $\dagger$ Fig. 3 and 4 . The Cd concentrations in all parts of Iris sibirica $\mathrm{L}$. increased with increasing amounts of spiked $\mathrm{Cd}$ in the solution (except for the leaf at $15.0 \mathrm{mg} \mathrm{L}^{-1} \mathrm{Cd}$ ). The highest Cd concentrations in tissues for Iris sibirica L. were found at the $25 \mathrm{mg} \mathrm{L}^{-1} \mathrm{Cd}$ treatment: Cd concentrations in root, stem, and leaf were $463.8,258.4,56.9 \mathrm{mg} \mathrm{kg}^{-1}$, respectively. The $\mathrm{Cd}$ content in the root is much higher than that in the stem or leaf, probably being ascribed to the limited transport of heavy metals from roots to shoots. This phenomenon is in agreement with the earlier reports regarding the absorption of Cd by Baumea juncea, Baumea articulata, Schoenoplectus validus and Juncus subsecundus. ${ }^{17}$ The distribution of Cd in the tissues of Cyperus alternifolius L. was similar to Iris sibirica $\mathrm{L}$. The Cd concentrations in roots were even higher compared with Iris sibirica L. In
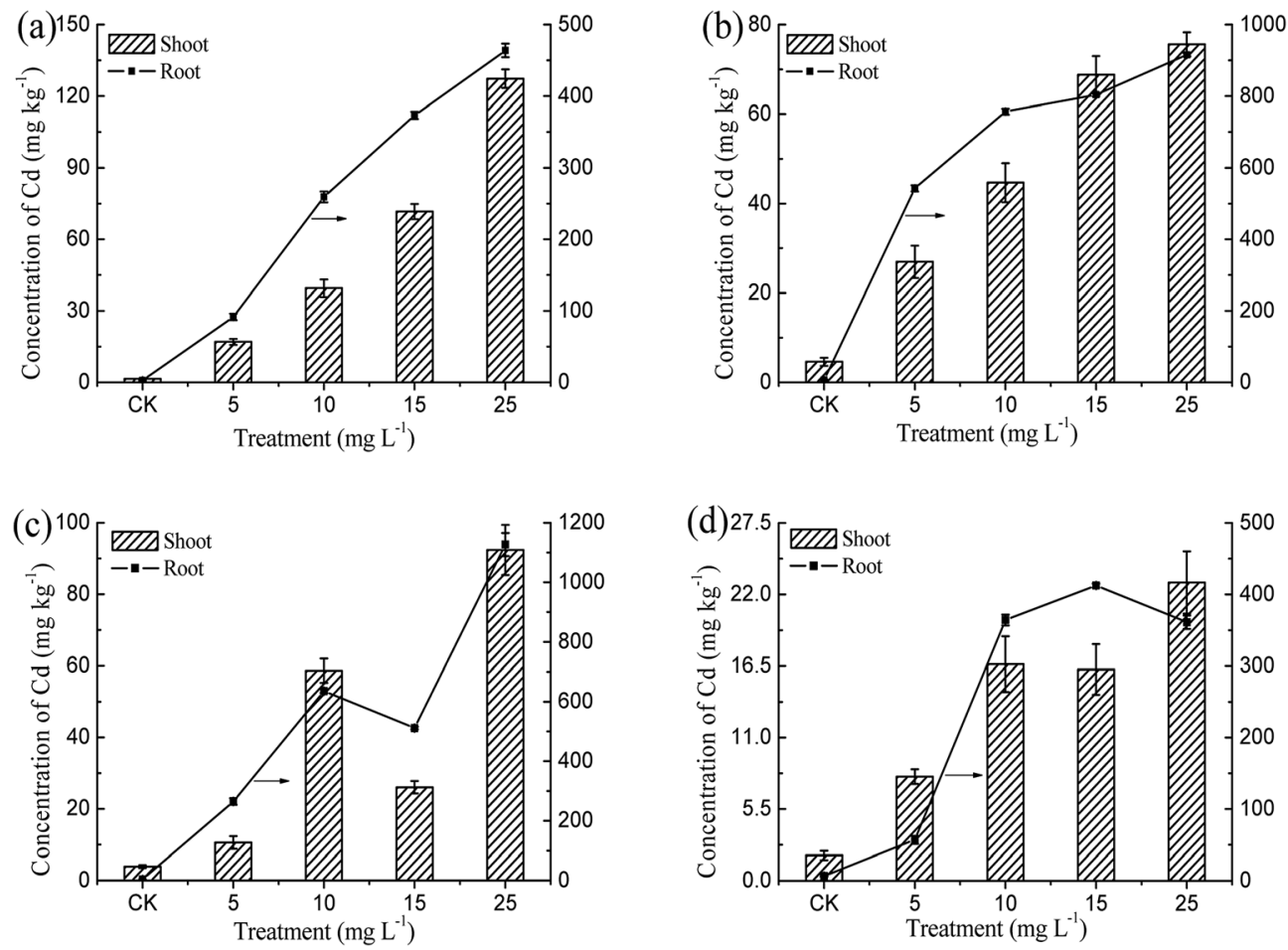

Fig. 3 Concentration of $\mathrm{Cd}$ in wetland emergent plants under Cd treatments: (a) Iris sibirica L., (b) Cyperus alternifolius L., (c) Typha orientalis Presl, and (d) Acorus calamus L. Note: shoot Cd concentration is calculated as: $\left(C_{\text {stem }} \times M_{\text {stem }}+C_{\text {leaf }} \times M_{\text {leaf }}\right) /\left(M_{\text {stem }}+M_{\text {leaf }}\right)$, where $C$ is the concentration of $\mathrm{Cd}$ and $M$ is the biomass of plant. 

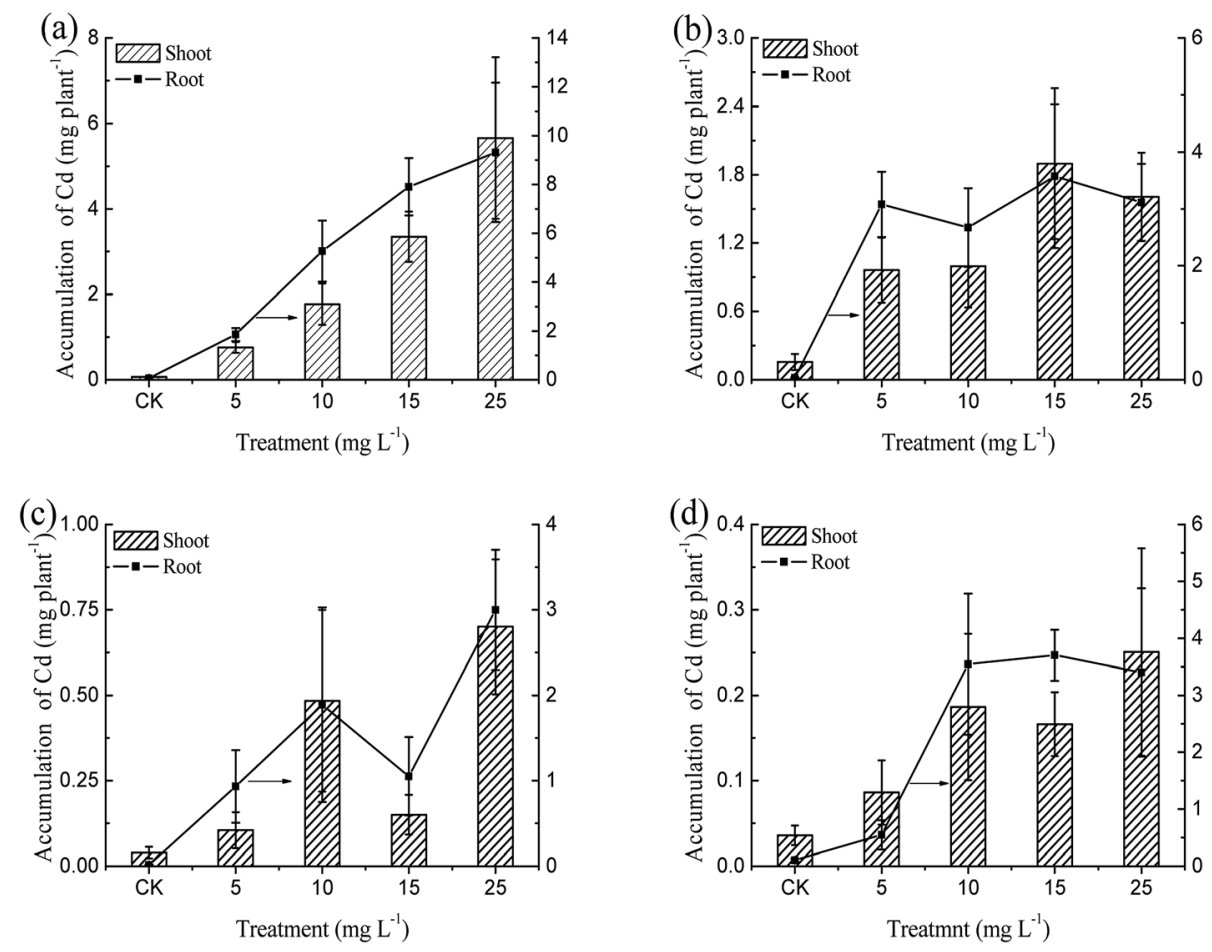

Fig. 4 Accumulation of $\mathrm{Cd}$ in wetland emergent plants under Cd treatments: (a) Iris sibirica L., (b) Cyperus alternifolius L., (c) Typha orientalis Presl, and (d) Acorus calamus L. Note: shoot $C d$ accumulation is $\left(C_{\text {stem }} \times M_{\text {stem }}+C_{\text {leaf }} \times M_{\text {leaf }}\right)$, where $C$ is the concentration of $C d$ and $M$ is the biomass of plant.

the case of Typha orientalis Presl, the Cd concentrations in root, stem and leaf basically showed an ascending trend versus the concentration of spiked $\mathrm{Cd}$ and got the peak values at $25.0 \mathrm{mg} \mathrm{L}{ }^{-1} \mathrm{Cd}$. In regard to Acorus calamus L., the concentrations of $\mathrm{Cd}$ in root, stem and leaf did not show significant difference when the Cd supply was higher than $10.0 \mathrm{mg} \mathrm{L}^{-1}$, implying that the concentrations of Cd in Acorus calamus L. were almost independent of the exposure levels.

The Cd concentrations in the four emergent plants were both in the sequence: root $>$ stem $>$ leaf. The results suggested that plants accumulated a great amount of $\mathrm{Cd}$ in their tissues, and a large portion of $\mathrm{Cd}$ was stored in the roots and the rest was translocated to the shoots. This is in agreement with previous report that most of $\mathrm{Cd}$ accumulated in the roots of sugarcane. ${ }^{25}$ Similar results were also observed for the uptake of arsenic by winter wheat. ${ }^{26}$ It appears that Cd(II) metal move predominately into the root apoplast and accumulate near the endodermis. The endodermis acts as a partial barrier to the movement of heavy metals between roots and shoots. ${ }^{25}$ The barrier effect also explained the nice tolerance of Iris sibirica L. to high concentration of $\mathrm{Cd}$ in hydroponic solution.

Generally, the normal level of Cd in most of plants was only $0.1 \mathrm{mg} \mathrm{kg}^{-1}$, and the threshold value that is often used to define a Cd hyperaccumulator is $100.0 \mathrm{mg} \mathrm{kg}{ }^{-1}$ dry weight of shoots. ${ }^{2} \mathrm{~A}$ larger amount of heavy metals accumulated in the aboveground parts of a hyperaccumulator was conducive to shifting out metals from environment by harvesting the aboveground parts. ${ }^{27}$ As shown in Fig. 3, the total Cd concentration in shoots ranged from 1.5 to $127.3 \mathrm{mg} \mathrm{kg}^{-1}$. When the $\mathrm{Cd}$ concentration

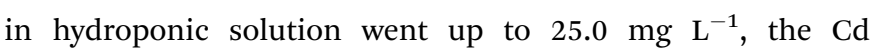
concentrations in the shoots of Iris sibirica L., Cyperus alternifolius L., Typha orientalis Presl and Acorus calamus L. reached maxima of $127.3,75.6,92.4$ and $22.9 \mathrm{mg} \mathrm{kg}^{-1}$, respectively. The concentration of $\mathrm{Cd}$ in the shoot of Iris sibirica L. exceeded the critical level of $100.0 \mathrm{mg} \mathrm{kg}^{-1}$, thus Iris sibirica $\mathrm{L}$. can be deemed as a Cd-hyperaccumulator. Meanwhile, Typha orientalis Presl also accumulated a large amount of $\mathrm{Cd}$ in the aboveground parts, and the concentration of $\mathrm{Cd}$ in shoots could accumulate $92.4 \mathrm{mg} \mathrm{kg}^{-1}$ under $25.0 \mathrm{mg} \mathrm{L}^{-1} \mathrm{Cd}_{\text {solution within }}$ 60 days. The results indicated that Typha orientalis Presl could be considered as a candidate for remedying Cd-contaminated sites.

The accumulation of $\mathrm{Cd}$ in four kinds of emergent plants also maximized under the $25.0 \mathrm{mg} \mathrm{L}^{-1}$ treatment. As shown in Fig. 4, the Cd accumulation in root and shoot of Iris sibirica L. reached 9.4 and $5.6 \mathrm{mg}$ per plant, respectively. Cd accumulation in the root accounted for $62 \%$ of the total Cd accumulation. This is similar to the Cd distribution in a terrestrial plant. Tissues of Solanum photeinocarpum extracted 157.0 and 138.0 $\mu \mathrm{g}$ per plant in roots and shoots at $60.0 \mathrm{mg} \mathrm{kg}^{-1} \mathrm{Cd}$ in soil: the accumulation in the root took up $53 \%$ of the total. ${ }^{28}$

Although the concentration of Cd in root of Iris sibirica L. was lower than that of Typha orientalis Presl, the overall uptake amount by Iris sibirica L. was far more than other emergent plants due to its large biomass. Correlation analysis showed that the concentrations and the accumulations of $\mathrm{Cd}$ in Iris sibirica L. were significantly positively related to the 


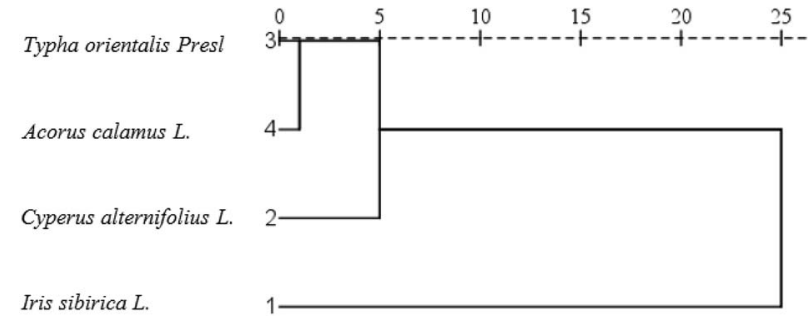

Fig. 5 Hierarchical cluster analysis of the accumulations among emergent plants.

concentrations of $\mathrm{Cd}$ in the hydroponic solution. The corresponding regression equations can be expressed as:

$$
\begin{aligned}
& Y_{\mathrm{CR}}=19.311 X+25.676\left(R^{2}=0.94^{* *}\right) \\
& Y_{\mathrm{CS}}=5.1651 X-5.4411\left(R^{2}=0.99^{* *}\right) \\
& Y_{\mathrm{AR}}=393.26 X+556.34\left(R^{2}=0.93^{* *}\right) \\
& Y_{\mathrm{AS}}=230.75 X-225.51\left(R^{2}=0.99^{* *}\right)
\end{aligned}
$$

where $Y_{\mathrm{CR}}$ and $Y_{\mathrm{CS}}$ are Cd concentrations in root and shoot of Iris sibirica L.; $Y_{\mathrm{AR}}$ and $Y_{\mathrm{AS}}$ are Cd accumulations in root and shoot of Iris sibirica L., respectively. $X$ is the concentration of Cd in hydroponic solution. The significant correlation indicated that the Cd accumulation in Iris sibirica L. may be further improved under the hydroponic condition higher than $25.0 \mathrm{mg} \mathrm{L}^{-1} \mathrm{Cd}$.

Hierarchical cluster analysis (HCA) is an unsupervised pattern detection method that partitions all cases into smaller groups or clusters of relatively similar cases that are dissimilar to other groups. The lower the distances between the samples, the more similar they are ${ }^{29} \mathrm{HCA}$ was performed on data of $\mathrm{Cd}$ accumulation, as shown in Fig. 5. The dendrogram shows the similarities and dissimilarities of accumulating ability between emergent plants. The samples of Typha orientalis Presl and Acorus calamus $\mathrm{L}$. formed the first cluster, indicating that the two samples were similar and accumulations of $\mathrm{Cd}$ are small. The more similar sample to this cluster was Cyperus alternifolius L., and the more dissimilar sample to the first cluster was Iris sibirica L. Overall, the Cd uptake capabilities of the emergent plants followed the decreasing order: Iris sibirica L. > Typha orientalis Presl > Cyperus alternifolius L. > Acorus calamus $\mathrm{L}$.

\subsection{Bioaccumulation factor (BCF) and translocation factor (TCF)}

The BCF value is an important index to reflect the capacity of plant to extract heavy metals from the surrounding environments. The BCF can be used to estimate the potential of a plant for phytoremediation, ${ }^{17}$ In general, plant species exhibiting BCF greater than 1.0 is suitable for the phytoextraction of metals. ${ }^{2}$ Under the exposure of Cd contamination, most of the BCF values for the four kinds of emergent plants were far more than one or very close to one (Fig. 6a). This observation suggested that the emergent plants used in this experiment all possessed the ability to uptake $\mathrm{Cd}$ heavy metal from the hydroponic solution.

In Fig. 6a, it is also observed that the BCF values of Iris sibirica $\mathrm{L}$. are positively correlated with the Cd concentration in hydroponic solution, indicating an increased efficiency of Cd accumulation in upground parts with increasing $\mathrm{Cd}$ concentrations in hydroponic solution. This is very different from the reported Cd accumulators. The BCF values of Solanum photeinocarpum, Arthrocnemum macrostachyum and Bidens pilosa were reportedly to decrease with increasing $\mathrm{Cd}$ concentrations: the relationship between the BCF values and $\mathrm{Cd}$ concentrations was negative and logarithmic linear, indicating a diminishing efficiency of $\mathrm{Cd}$ accumulation with increasing Cd concentrations. ${ }^{2,28,30}$ The increased BCF in this study further confirmed that the Iris sibirica $\mathrm{L}$. has a strong ability to extract $\mathrm{Cd}$ from the contaminated matrix. Unlike the Iris sibirica L., the BCF values of Cyperus alternifolius L. decreased with the increasing $\mathrm{Cd}$ concentration in hydroponic solution. This is probably due to the lower Cd-tolerance of Cyperus alternifolius $\mathrm{L}$. to increased Cd concentrations. Concerning the BCF values of Typha orientalis Presl, they showed a serious fluctuation with the Cd concentration. A pretty high value in BCFs of Typha orientalis Presl were found at $10.0 \mathrm{mg} \mathrm{L}^{-1} \mathrm{Cd}$, and the BCFs at $5.0,10.0 \mathrm{mg} \mathrm{L}^{-1}$ are lower than 2. The BCF values of Acorus calamus $\mathrm{L}$. were much lower compared to other emergent plants, and they were not strongly dependent on the hydroponic Cd concentration.

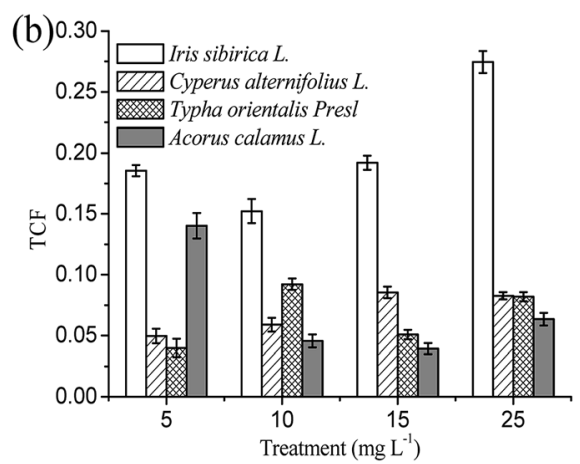

Fig. 6 BCF (a) and TCF (b) for Iris sibirica L., Cyperus alternifolius L., Typha orientalis Presl and Acorus calamus L. under different Cd concentrations (5 mg L $\mathrm{m}^{-1}, 10 \mathrm{mg} \mathrm{L}^{-1}, 15 \mathrm{mg} \mathrm{L}^{-1}, 25 \mathrm{mg} \mathrm{L}^{-1} \mathrm{Cd}$ ). Results are expressed as means \pm S.D. $(n=3)$.

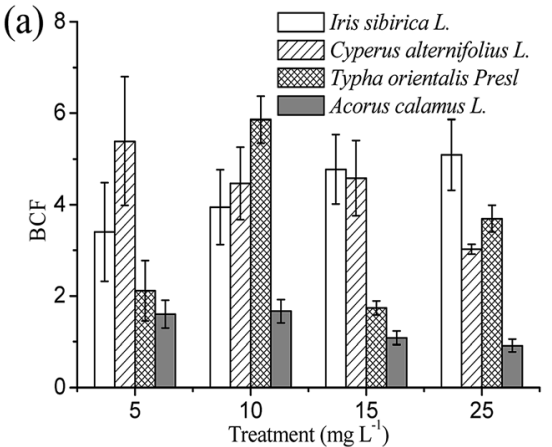


Higher TCF values may suggest that the plant can uptake Cd from soil and store them in the shoots with great efficiency, which indicates that the species have strong ability to transfer Cd from roots to shoots. ${ }^{2}$ TCFs of all the plant species were all less than one (Fig. 6b), indicating that these plant species were not efficient in translocating $\mathrm{Cd}$ metal to shoots. Among all the plants screened, Iris sibirica $\mathrm{L}$. had the highest TCF (0.15-0.27), but did not show any significant changes under all $\mathrm{Cd}$ treatments. The higher TCF values among all the emergent plants were Iris sibirica L., this evidenced Iris sibirica L. has stronger ability to translocate the Cd heavy metal from roots to the upground shoots. Susana et al. reported that the TCF values of Arthrocnemum macrostachyum were 0.97 and 1.03 for 0.05 and $0.20 \mathrm{mmol} \mathrm{L}^{-1} \mathrm{Cd}$ in hydroponic solution, respectively. ${ }^{30}$ The TCF values of $B$. pilosa at the flowering and mature stages were 1.3-7.4 and 1.9-14.4 for Cd extraction from soils, respectively. ${ }^{2}$ These terrestrial plants showed higher TCF values than Iris sibirica L. However, from a perspective of practical application, the TCF value may not an important criterion for the phytoremediation of wet soil by emergent plants because their roots and shoots can be harvested easily.

\section{Conclusion}

The present study investigated the cadmium tolerance and accumulation characteristics of four emergent plants. Among all the studied emergent plants, Iris sibirica L. had the greatest tolerance to $\mathrm{Cd}$ stresses and the strongest Cd uptake ability under hydroponic culture condition. The concentration of $\mathrm{Cd}$ in shoots of Iris sibirica $\mathrm{L}$. was more than $100.0 \mathrm{mg} \mathrm{kg}^{-1}$ under the hydroponic condition of $25.0 \mathrm{mg} \mathrm{\textrm {L } ^ { - 1 }} \mathrm{Cd}$, which reached the standard of defining a Cd-hyperaccumulator. Meanwhile, significant correlation was found between $\mathrm{Cd}$ accumulation in Iris sibirica $\mathrm{L}$. and the concentrations of $\mathrm{Cd}$ in the hydroponic solution, which indicated that the $\mathrm{Cd}$ accumulation in Iris sibirica L. may be further improved under the hydroponic condition higher than $25.0 \mathrm{mg} \mathrm{L}^{-1} \mathrm{Cd}$. The BCF of Iris sibirica $\mathrm{L}$. was higher than 1 and increased with increasing $\mathrm{Cd}$ concentration in hydroponic solution, which further confirmed the hyperaccumulation characteristics of Iris sibirica L. Although field studies are needed to test the its performance for extracting $\mathrm{Cd}$ from real wet soil, the findings of this work have demonstrated the potential of Iris sibirica $\mathrm{L}$. as an engineering Cd-hyperaccumulator.

\section{Conflicts of interest}

There are no conflicts to declare.

\section{Acknowledgements}

This work was kindly supported by the National Science and Technology Major Project of China (2016ZX05040001), Central Level, Scientific Research Institutes for Basic R\&D Special Fund Business (201409030, 2014-GZ-006).

\section{References}

1 M. Adrees, S. Ali, M. Rizwan, M. Zia-Ur-Rehman, M. Ibrahim, F. Abbas, M. Farid, M. F. Qayyum and M. K. Irshad, Mechanisms of silicon-mediated alleviation of heavy metal toxicity in plants: A review, Ecotoxicol. Environ. Saf., 2015, 119, 186-197.

2 Y. Sun, Q. Zhou, W. Lin and W. Liu, Cadmium tolerance and accumulation characteristics of Bidens pilosa $L$. as a potential Cd-hyperaccumulator, J. Hazard. Mater., 2009, 161, 808-814.

3 S. C. Wu, K. C. Cheung, Y. M. Luo and M. H. Wong, Effects of inoculation of plant growth-promoting rhizobacteria on metal uptake by Brassica juncea, Environ. Pollut., 2006, 140, 124-135.

4 M. I. Rucandio, M. D. Petit-Domínguez and R. GarcíaGiménez, Biomonitoring of chemical elements in an urban environment using arboreal and bush plant species, Environ. Sci. Pollut. Res., 2011, 18, 51-63.

5 C. Keller, M. Rizwan, J. C. Davidian, O. S. Pokrovsky, N. Bovet, P. Chaurand and J. D. Meunier, Effect of silicon on wheat seedlings (Triticum turgidum L.) grown in hydroponics and exposed to 0 to $30 \mu \mathrm{M} \mathrm{Cu}$, Planta, 2015, 241, 847-860.

6 S. Ali, A. Chaudhary, M. Rizwan, H. T. Anwar, M. Adrees, M. Farid, M. K. Irshad, T. Hayat and S. A. Anjum, Alleviation of chromium toxicity by glycinebetaine is related to elevated antioxidant enzymes and suppressed chromium uptake and oxidative stress in wheat (Triticum aestivum L.), Environ. Sci. Pollut. Res., 2015, 22, 10669-10678.

7 A. A. Belimov, N. Hontzeas, V. I. Safronova, S. V. Demchinskaya, G. Piluzza, S. Bullitta and B. R. Glick, Cadmium-tolerant plant growth-promoting bacteria associated with the roots of Indian mustard (Brassica juncea L. Czern.), Soil Biol. Biochem., 2005, 37, 241-250.

8 Y. Fushiwaki and K. Urano, Adsorption of pesticides and their biodegraded products on clay minerals and soils, $J$. Health Sci., 2001, 47, 429-432.

9 S. L. Doty, Enhancing phytoremediation through the use of transgenics and endophytes, New Phytol., 2010, 179, 318333.

10 M. N. V. Prasad, Phytoremediation of Metal-Polluted Ecosystems: Hype for Commercialization, Russ. J. Plant Physiol., 2003, 50, 686-701.

11 K. Perronnet, C. Schwartz and J. L. Morel, Distribution of cadmium and zinc in the hyperaccumulator Thlaspi caerulescens grown on multicontaminated soil, Plant Soil, 2003, 249, 19-25.

12 X. E. Yang and P. J. Stoffella, Cadmium tolerance and hyperaccumulation in a new Zn-hyperaccumulating plant species (Sedum alfredii Hance), Plant Soil, 2004, 259, 181189.

13 S. D. Ebbs and L. V. Kochian, Toxicity of Zinc and Copper to Brassica Species: Implications for Phytoremediation, $J$. Environ. Qual., 1997, 26, 776-781. 
14 J. S. Dunbabin and K. H. Bowmer, Potential use of constructed wetlands for treatment of industrial wastewaters containing metals, Sci. Total Environ., 1992, 111, 151-168.

15 D. P. Phillips, H. Lrd and J. B. Adams, Wetland plants as indicators of heavy metal contamination, Mar. Pollut. Bull., 2015, 92, 227-232.

16 M. L. Pompêo, R. Henry and V. Moschini-Carlos, The water level influence on biomass of Echinochloa polystachya (Poaceae) in the Jurumirim Reservoir (São Paulo, Brazil), Braz. J. Biol., 2001, 61, 19.

17 C. Mânzatu, B. Nagy, A. Ceccarini, R. Iannelli, S. Giannarelli and C. Majdik, Laboratory tests for the phytoextraction of heavy metals from polluted harbor sediments using aquatic plants, Mar. Pollut. Bull., 2015, 101, 605-611.

18 P. A. Sainger, R. Dhankhar, M. Sainger, A. Kaushik and R. P. Singh, Assessment of heavy metal tolerance in native plant species from soils contaminated with electroplating effluent, Ecotoxicol. Environ. Saf., 2011, 74, 2284-2291.

19 E. W. I. Hajar, A. Z. B. Sulaiman and A. M. M. Sakinah, Assessment of Heavy Metals Tolerance in Leaves, Stems and Flowers of Stevia Rebaudiana Plant, Procedia Environ. Sci., 2014, 20, 386-393.

20 O. Jitar, C. Teodosiu, A. Oros, G. Plavan and M. Nicoara, Bioaccumulation of heavy metals in marine organisms from the Romanian sector of the Black Sea, New Biotechnol., 2015, 32, 369-378.

21 N. Caille, F. J. Zhao and S. P. Mcgrath, Comparison of root absorption, translocation and tolerance of arsenic in the hyperaccumulator Pteris vittata and the nonhyperaccumulator Pteris tremula, New Phytol., 2010, 165, 755-761.

22 Z. Yanqun, L. Yuan, C. Jianjun, C. Haiyan, Q. Li and C. Schvartz, Hyperaccumulation of $\mathrm{Pb}, \mathrm{Zn}$ and $\mathrm{Cd}$ in herbaceous grown on lead-zinc mining area in Yunnan, China, Environ. Int., 2005, 31, 755-762.

23 B. Wang, J. Wang, H. Zhao and H. Zhao, Stress induced plant resistance and enzyme activity varying in cucumber, Colloids Surf., B, 2006, 48, 138-142.
24 S. H. Wei and Q. X. Zhou, Identification of weed species with hyperaccumulative characteristics of heavy metals, Prog. Nat. Sci.: Mater. Int., 2004, 14, 495-503.

25 Z. Xin, Y. G. Zhu, Y. B. Zhang, Y. X. Liu, S. C. Liu, J. W. Guo, R. D. Li, S. L. Wu and B. D. Chen, Growth and metal uptake of energy sugarcane (Saccharum spp.) in different metal mine tailings with soil amendments, J. Environ. Sci., 2014, 26, 1080-1089.

26 Q. Liu, H. U. Chengxiao, Q. Tan, X. Sun, S. U. Jingjun, Y. Liang, Q. Liu, H. U. Chengxiao, Q. Tan and X. Sun, Effects of As on As uptake, speciation, and nutrient uptake by winter wheat (Triticum aestivum L.) under hydroponic conditions, J. Environ. Sci., 2008, 20, 326-331.

27 Y. Sun, Q. Zhou and C. Diao, Effects of cadmium and arsenic on growth and metal accumulation of Cd-hyperaccumulator Solanum nigrum L, Bioresour. Technol., 2008, 99, 1103-1110.

28 X. Zhang, H. Xia, Z. Li, P. Zhuang and B. Gao, Identification of a new potential Cd-hyperaccumulator Solanum photeinocarpum by soil seed bank-metal concentration gradient method, J. Hazard. Mater., 2011, 189, 414-419.

29 F. Zhou, H. Guo, Y. Liu and Y. Jiang, Chemometrics data analysis of marine water quality and source identification in Southern Hong Kong, Mar. Pollut. Bull., 2007, 54, 745-756.

$30 \mathrm{~S}$. Redondogómez, E. Mateosnaranjo and L. Andradesmoreno, Accumulation and tolerance characteristics of cadmium in a halophytic Cdhyperaccumulator, Arthrocnemum macrostachyum, $J$. Hazard. Mater., 2010, 184, 299-307.

31 X. Li, W. L. Yang, H. He, S. Wu, Q. Zhou, C. Yang, G. Zeng, L. Luo and W. Lou, Responses of microalgae Coelastrella sp. to stress of cupric ions in treatment of anaerobically digested swine wastewater, Bioresour. Technol., 2017, 251, 274.

32 S. Wu, Z. Shen, C. Yang, Y. Zhou, X. Li, G. Zeng, S. Ai and $\mathrm{H}$. He, Effects of $\mathrm{C} / \mathrm{N}$ ratio and bulking agent on speciation of $\mathrm{Zn}$ and $\mathrm{Cu}$ and enzymatic activity during pig manure composting, Int. Biodeterior. Biodegrad., 2016, 119, 429-436.

33 U. S. Dissanayake, K. U. Tennakoon and N. Priyantha, Potential of two invasive plant species, Lantana camara L. and Wedelia trilobata L., for selective heavy metal uptake, Ceylon J. Sci., Biol. Sci., 2002, 29, 1-11. 